\title{
STUDENT AS A PERFORMER OF FLIPPED LEARNING IN MATHEMATICS UPGRADED WITH INTERACTIVE VIDEO
}

\author{
Elena Rudolf \\ Secondary School of Economics Maribor, Slovenia
}

\begin{abstract}
Flipped learning represents an active and effective learning method with a focus on students, to whom new subject matter was introduced in advance. By using flipped learning, it is possible to evolve collaborative peer-work, explore the teaching content more efficiently, evolve students' critical thinking and create new opportunities for learning, in which students develop new mathematical problems by themselves, based on the discussed content.

With the substitution of teacher's and student's role and preliminary autonomous studying of new teaching contents the student performing flipped learning gained new skills and was able to develop his autonomy. Other students from the experimental group played an active role in the process of studying at home and in the classroom, while the teacher was merely the moderator and advisor throughout the learning process. The time intended for checking homework in traditional lessons was spent on mutual collaboration, research of mathematical concepts and seeking answers to nascent questions. The findings of this mini research point to a significant difference in the understanding of discussed mathematical concepts and students' motivation for learning in favour of the experimental group.

The method of flipped learning with use of ICT and teacher's support represents an effective and creative way of learning. The aim of this research is to examine how the student can take the role of flipped learning performer and, with support of the teacher, create his own video with interactive tasks in application EdPuzzle. The impact of flipped learning and use of applications on motivation for learning, understanding, permanence of knowledge and progress of self-regulation are brought to the centre of attention.
\end{abstract}

Keywords: flipped learning, interactive video, Ed Puzzle, effective use of applications

\section{Introduction}

Flipped learning (flipped classroom) is one of the most recent didactic methods, which integrates online learning with learning in classroom. Supported by information and communications technology (ICT), this approach empowers the student to shift from a passive role of a listener to an active role of a creator and performer of the learning process. On the other hand, Aberšek and Fiksl (2014) talked about establishing a positive atmosphere in the classroom when introducing changes in the learning process.

Integration of flipped learning in math lessons is a relative novelty. Therefore, the objective of the research was to check reasonableness of this method. In the research the following hypothesis were formed:

- $\quad$ H1: Flipped learning, upgraded with the use of online applications and tools, extends the understanding of mathematical contents.

- $\quad$ H2: Flipped learning, upgraded with the use of interactive video, enables self-regulation of students' learning process.

- $\quad$ H3: Flipped learning, upgraded with ICT, expands students' motivation for learning. 
According to the opinion of many scientists, the use of modern ICT in mathematical curriculum significantly contributes to positive results in learning and understanding of mathematical concepts (Lazakidou, 2010). Researchers and teachers-practitioners have developed numerous alternative teaching strategies and learning methods for the integration and motivation of students in the learning process. Flipped learning is one such alternative.

Traditional learning focuses on the teaching content and the teacher, whereas flipped learning is based on students' educational needs (Bergmann \& Sams, 2012). Digital technologies enable a shift from classroom environment to individual learning environment of a single student, usually by using a video.

Jonathan Bergmann and Aaron Sams, teachers of chemistry from Colorado, who video-recorded the first teaching contents and published them for their students on the internet in 2007, are listed as authors of flipped learning. Many researchers describe flipped learning as a model where the teacher prepares video recordings for a particular subject matter and publishes them on the net. The students then watch the video recordings before its discussion in the classroom and thus the time spent in the classroom is intended to in-depth analysis of the teaching content, collaborative peer-work, problem solving and discussion (Bergmann, 2013), (Chen, 2014), (Fautch, 2015), (Hughes, 2012).

The effect of self-regulation is quoted as an advantage of flipped learning by didactic scientists due to the fact that students can select their own learning pace and they can learn anywhere and anytime (Davies, 2013). The consequence of this is the shift from teachercentred learning to student centred learning (Kong, 2014), (Honeycutt, 2014). Flipped learning has a pronounced impact on motivation and understanding of mathematical concepts with weaker students (Bhagat, 2016) since the teacher can offer them more individual teaching support. On the other hand, more talented students can solve several problem assignments and can participate in discussion more actively. The time spent in the classroom is therefore more effective and goal oriented. The teacher can create several opportunities for integration and use of knowledge as well as active usage of cognitive functions of higher level.

The formative feedback obtained during flipped learning helps the teacher to clarify the teaching content and possible false notions of the students while the students are provided with the possibility to organize the new knowledge in the way that will be more appropriate for their further use (Brame, 2013).

\section{Research Methodology}

With the intent of finding out whether a student can take over the role of a flipped learning performer instead of the teacher, and how they are going to manage this role, a mini research was carried out. 14 third-class students of secondary school filled out a survey after performed flipped learning. Its aim was to check the effect of use of online applications, tools, and interactive video on the learning process.

Based on the analysis of a survey questionnaire and with comparative analysis of written test results of the students in experimental group and students of the other section, integrated in the same educational programme and taught traditionally, interesting findings were established.

After successfully using the method of flipped learning in discussing several learning contents, one of the students that are more successful voluntarily expressed a wish to test himself as a flipped learning performer. With the teacher's guidance, the student of the 
experimental group independently studied a definite learning content - Polynomial graph. With teacher's guidelines and support he made an authorial video recording with the use of the online tool Screencast-O-matic, in which he, in accordance with the didactic principle of gradualness, showed the procedure of drawing a polynomial graph step by step. In addition, he didactically upgraded the video into an interactive form with application EdPuzzle. The video recording was posted in the online tool EdPuzzle and the students had access to it through their virtual math classroom.

Here is the link: https://edpuzzle.com/media/5dd7c53a33c1d440b867ebd4

\section{Figure 1}

Tasks for Students in Interactive Video

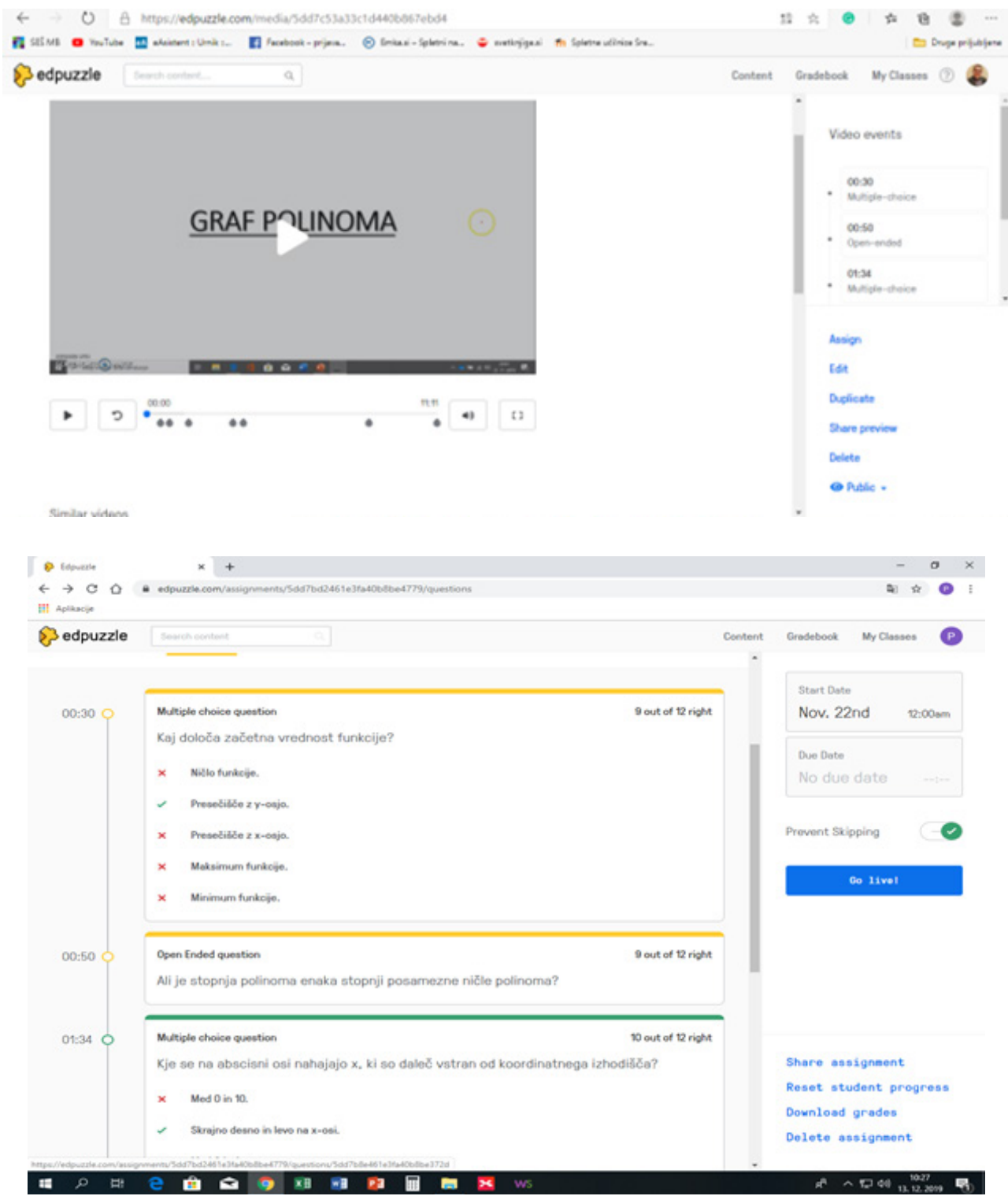


The students of the experimental group watched the video recording in EdPuzzle individually before the school lesson. They answered questions in a video and checked immediate feedback and correctness of their responses. In this way, they developed self-regulation since they chose time and space for learning individually and prepared summaries and questions in case of incomprehension or need for additional knowledge. Students could watch the video recording on smart devices anywhere and anytime (at home, on the way home, on the bus, on the train, at the library, in the hall) - as many times as they wanted.

After the student's individual work at home, the student performed flipped learning prepared worksheets with the help of the teacher. The worksheets encompassed a collection of different tasks for revising and analysis or research of particular examples. During the lessons, the students experienced collaborative peer-work. Each student participated constructively and shared their knowledge with other members of this heterogeneous group and received feedback. Each group investigated their own examples of polynomial graphs and prepared open questions on the addressed topic for classmates, which were later discussed in the plenary part of the lesson.

\section{Research Results}

The effects of flipped learning with contemporary use of interactive video on learning process are the most evident from the answers to the fourth and sixth questions in the survey, which was passed to the students of the experimental group in the virtual classroom.

\section{Figure 2}

The Impact of Use of Online Applications and Tools on Student's Learning Process

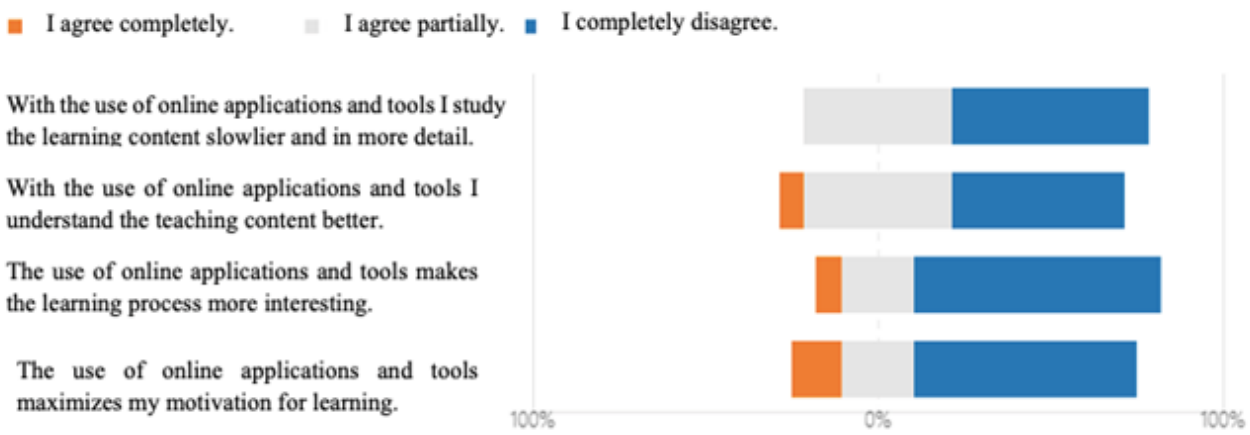

All the participants believe that the use of online applications and tools enables a slower and more detailed discussion of learning content, while $92.9 \%$ of them understand the teaching content better.

More than $85 \%$ of students believe that the use of online applications and tools diversifies the learning process and maximizes their motivation for learning, which is quite a revealing data.

As shown in Figure 3, all students think that they are able to manage and control their own learning process independently with the use of interactive video, since they were able to select the space, time and pace of learning as well as the number of repeated 
video watching completely autonomously. $92.8 \%$ of students believe they have discussed the teaching content more slowly and more in-depth, as well as in a more interesting and amusing way, using interactive video. This approach motivated them for further exploration.

According to a unified opinion of the participants, the feedback they got with interactive video could fill gaps in their knowledge; in addition, using an interactive video contributed to a better understanding of new learning content due to fact that they could examine the study material multiple times.

\section{Figure 3}

Use of Interactive Video and Its Impact on Learning Process

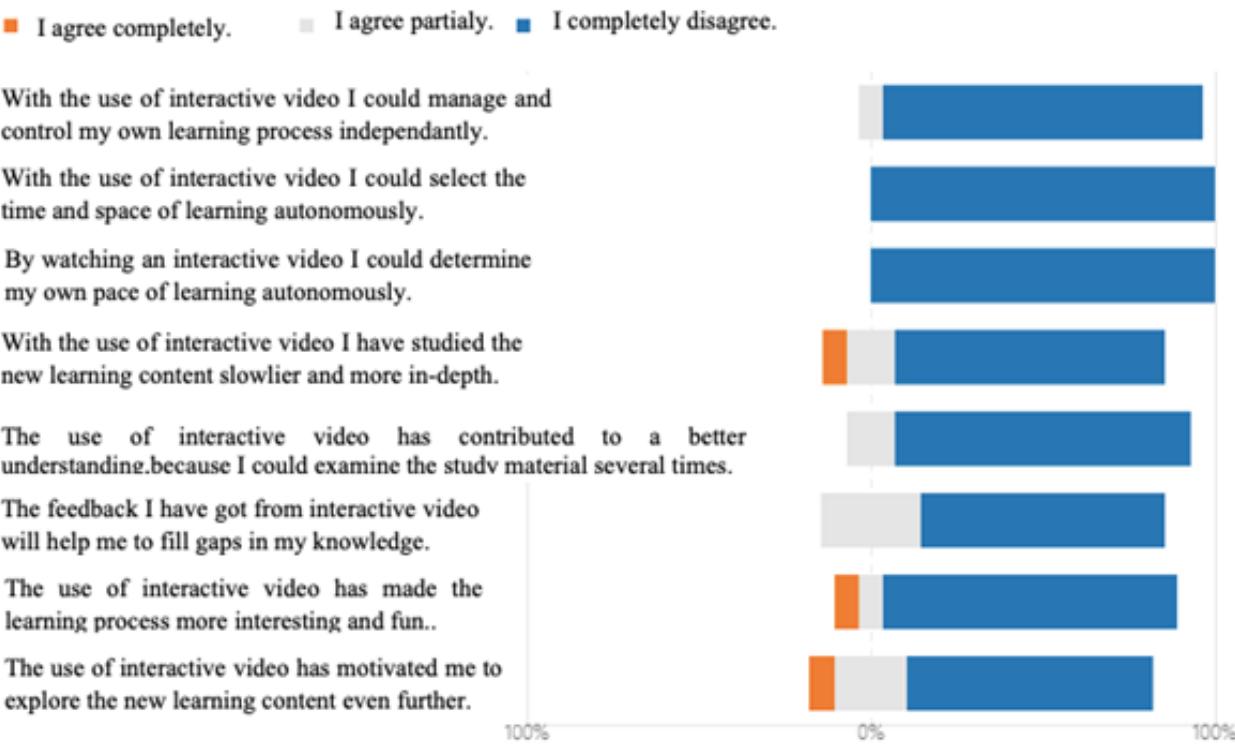

\section{Discussion}

According to the students from the experimental group, the autonomy and freedom of choosing the time and space of one's own learning have a positive influence on understanding the subject matter, and on the motivation for learning. This indicates a strong effect of self-regulation in flipped learning and confirms hypothesis $\mathrm{H} 2$, and the same viewpoint is supported by Davies et al. (2013).

After watching the video in advance, students were better prepared for the use of information in new situations, i.e., when given new assignments. They participated in discussions more effectively, came to quicker and better conclusions, and achieved a higher level of understanding of the subject matter under discussion.

During the lessons, both the teacher and the student, as a performer of flipped learning, acting as both supervisors and advisors, are able to make a differentiation and adjust to various individual students' needs. Namely, some students have focused on basics, while others have dealt with more difficult mathematical challenges. Flipped learning has enabled individualization and differentiation among students and an active participation of weaker students, who were not left alone with their home assignment, but 
could collaboratively work, with the help of classmates and teacher, clear up any confusion and assimilate more demanding mathematical concepts. Through collaborative peer-work students have learned from each other and they have not just acquired correct solutions and solving procedures, but they have also learned how to explain to their classmates why solutions in question were correct. In collaboration with the student as a performer of flipped learning, teachers have much more time for observing and advising the students and providing them feedback about their progress. Students were helped in developing their process routine, which gave them a feeling of a greater control over their own learning process.

Students see the main advantage of flipped learning in the possibility of renewed and multiple video watching, particularly those parts which were perhaps falsely understood during first viewing or had to be refreshed, or were especially interesting to them. In their opinion, this essentially contributes to a better understanding of teaching content. This confirms hypothesis H1, since students researched the learning content more slowly and more detailed in this process.

The analysis of the written test results, in which the knowledge of polynomial was evaluated and graded for students of both the experimental group and the ones who were taught traditionally, showed a significant difference between achievements of weaker students in both sections. In experimental group only three students did not achieve $50 \%$ points, while six students taught traditionally were unsuccessful. In addition, the average grade of written test was higher with students of experimental group and totalled at 2.9 out of 5, whereas with the students of the other section the average grade came only to 2.4, although there is no difference among them. These results have thus confirmed the influence of flipped learning on motivation and understanding of mathematical concepts with weaker students (Bhagat et al., 2016).

Similarly to Brame (Brame, 2013), the students have stressed the importance of feedback they got from the student performing flipped learning and from the teacher, which has helped them to fill the gaps in their knowledge, has enabled to expand their knowledge and has motivated them for further exploration and deepening in accordance with hypothesis $\mathrm{H} 3$.

The findings of this mini research point to a significant difference in the understanding of the discussed mathematical concepts and students' motivation for learning in favour of the experimental group.

\section{Conclusions}

The approach of flipped learning represents an intense, effective, and creative way of learning because it shifts priorities - from the process of merely studying the content, to mastering it. Classroom interaction provides students with sufficient autonomy and freedom, enabling them to form their own learning means. The teacher is able to maximize the interaction in the classroom, to check the understanding and create a synthesis of teaching contents. Students are actively integrated in knowledge formation since they are offered opportunities for collaboration and evaluation of their learning process with a certain personal note.

The added value of flipped learning, assisted by ICT, lies in increased understanding of mathematical teaching contents, in achievement of knowledge permanence and in developing of self-regulation in the planning phase of student learning. Moreover, flipped 
learning increases students' motivation for learning, develops collaborative peer-work and maximizes individual treatment of the students. Following this year's positive experience of using flipped learning for teaching Polynomials in the third grade of secondary school, the plan is to extend this didactic method onto the following school year and to test its use in circumstances of distance education.

\section{References}

Aberšek, B., \& Fiksl, M. (2014). Classroom climate as a part of contemporary didactical approaches. Problems of Education in the 21 st Century, 61, 28-36. http://www.scientiasocialis.lt/pec/node/916

Bergmann, J. O. (2013). The Flipped Class: Myths vs. Reality. The Daily Riff.

Bergmann, J., \& Sams, A. (2012). Flip your classroom: Reach every student in every class every day. ISTE, ASCD.

Bhagat, K. K. (2016). The impact of the flipped classroom on mathematics concept learning in high school. Journal of Educational Technology \& Society, 19, 134-142. https://www.jstor.org/ stable/jeductechsoci.19.3.134

Brame, C. J. (2013). Flipping the classroom. Vanderbilt University Center for Teaching.

Chen, Y., Wang, Y., Kinshuk, \& Chen, N.-S. (2014). Is FLIP enough? Or should we use the FLIPPED model instead? Computers and Education, 79, 16-27. https://doi.org/10.1016/j.compedu.2014.07.004

Davies, R. S. (2013). Flipping the classroom and instructional technology integration in a collegelevel information systems spreadsheet course. Educational Technology Research and Development, 61, 563-580. https://doi.org/10.1007/s11423-013-9305-6

Fautch, J. M. (2015). The Flipped classroom for teaching organic chemistry in small classes: Is it effective? Chemistry Education Research and Practice, 16(1), 179186. https://doi.org/10.1039/C4RP00230J

Honeycutt, B., \& Garrett, J. (2014). Expanding the definition of a flipped learning environment. Faculty focus Online. https://www.facultyfocus.com/articles/blended-flipped-learning/ expanding-definition-flipped-learning-environment/

Hughes, H. (2012). Introduction to flipping the college classroom. EdMedia 2012--World Conference on Educational Media and Technology (pp. 2434-2438). Association for the Advancement of Computing in Education (AACE).

Kong, S. C. (2014). Developing information literacy and critical thinking skills through domain knowledge learning in digital classrooms: An Experience of practicing flipped classroom strategy. Computers and Education, 78, 160-173. https://doi.org/10.1016/j. compedu.2014.05.009

Lazakidou, G., \& Retalis, S. (2010). Using computer supported collaborative learning strategies for helping students acquire self-regulated problem-solving skills in mathematics. Computers \& Education, 54(1), 3-13. https://doi.org/10.1016/j.compedu.2009.02.020

Received 22 April 2021; Accepted 22 June 2021

Cite as: Rudolf, E. (2021). Student as a performer of flipped learning in mathematics upgraded with interactive video. Gamtamokslinis ugdymas / Natural Science Education, 18(1), 22-28. https://doi.org/10.48127/gu-nse/21.18.22

\section{Elena Rudolf}

Teacher, Secondary School of Economics Maribor, Trg Borisa Kidriča 3, Maribor, Slovenia.

E-mail: elena.rudolf@ses-mb.si 